\title{
FECHO EPISTÊMICO, CETICISMO E RAZÕES CONCLUSIVAS
}

\author{
Stanley Kreiter Bezerra Medeiros*
}

\section{Resumo}

O fecho epistêmico é o princípio que diz que o conhecimento é fechado sob implicação. Se alguém sabe que uma proposição $P$ é o caso e, além disso, igualmente sabe que $P$ implica logicamente $Q$, então esse alguém também deve saber que $Q$ é o caso. Este princípio lógico é geralmente associado a problemas de vários tipos, tais como "onisciência lógica" e ceticismo. Para evitar a adoção do ceticismo ou devido a alguma concepção específica acerca do conhecimento, alguns autores preferem rejeitá-lo. De acordo com a "teoria das razões conclusivas" de Dretske, "conhecer $P$ " é equivalente a " $R$ não seria o caso se $P$ não fosse o caso" (sendo $R$ o conjunto de razões que dão apoio à verdade de $P$ ). Tal concepção implica claramente na rejeição do fecho epistêmico nos casos em que este princípio é associado a hipóteses céticas. Este artigo investiga a relação entre fecho epistêmico, ceticismo e a teoria das razões conclusivas de Dretske. Ao final, nossa análise sugere que "o desafio de Dretske", tal como é conhecido, não foi satisfatoriamente resolvido e encontra-se em aberto na epistemologia.

Palavras-chave: Ceticismo. Epistemologia. Fecho epistêmico. Razões conclusivas.

\begin{abstract}
Epistemic closure is the principle that says that knowledge is closed under known entailment. If one knows that some proposition $P$ is the case and, beside of that, equally knows that $P$ logically implies $Q$, then one must also know that $Q$ is the case. This logical principle is generally associated with problems of various sorts, such as "logical omniscience" and skepticism. To avoid embracing skepticism or due to some specific conception regarding knowledge, some authors prefer to reject it. According to Dretske's "theory of conclusive reasons", "knowing $P$ " is equivalent to " $R$ would not be the case if $P$ were not the case" $(R$ being the reasons supporting the true of $P$ ). Such conception clearly implies the denial of the epistemic closure in cases in which it is associated with skeptical hypotheses. This paper investigates the relation between epistemic closure, skepticism and Dretske's theory of conclusive reasons. In the end, our analysis suggests that the "Dretske's challenge", as it is known, was not solved satisfactorily and is still open in mainstream epistemology.
\end{abstract}

Key words: Skepticism. Epistemology. Epistemic closure. Conclusive reasons.

\section{INTRODUÇÃO}

\footnotetext{
* Doutor em Filosofia e Professor do Instituto Federal de Educação, Ciência e Tecnologia do Rio Grande do Norte. E-mail: stanley.medeiros@ifrn.edu.br.CV: http://lattes.cnpq.br/3243626132252618.
} 
O fecho epistêmico é o princípio lógico que estabelece que o conhecimento é fechado sob implicação, ou modus ponens. Em outras palavras, se um agente $S$ qualquer sabe que uma proposição $P$ é caso e, além disso, igualmente sabe que $P$ implica outra proposição, $Q$, então o agente em questão também deve saber que $Q$ é o caso. Assim, se $S$ acredita em $Q$ a partir da base segura fornecida pelas premissas (ele sabe que $P$ é o caso e que $P$ implica $Q$ ), então ele também deve saber que $Q$ é o caso.

Apesar de sua plausibilidade, o princípio do fecho epistêmico tem sido submetido a inúmeras críticas e contraexemplos (DE ALMEIDA, 2007). Desde 1970, Fred Dretske é tido como um dos maiores representantes dos que sustentam a invalidade do fecho para o operador de conhecimento ${ }^{1}$. Segundo ele, a aceitação do referido princípio leva inevitavelmente ao ceticismo. Certas proposições são denominadas "céticas" quando seu conteúdo assertivo é constituído por alguma hipótese cética. Entre as proposições céticas mais famosas, estão "sou uma marionete do gênio maligno" ou "sou um cérebro numa cuba". Uma hipótese cética passa a ser problemática na medida em que é considerada seriamente ou, ainda, quando sua negação é a conclusão de um argumento válido. Por exemplo:

"Sei que tenho duas mãos. Sei que, se tenho duas mãos, então não sou um cérebro numa cuba. Portanto, também sei que não sou um cérebro numa cuba."

A forma geral do argumento acima ("sei que $P$ ", "sei que $P$ implica $n \tilde{o} o-Q$ ", "sei que $n \tilde{a} o-Q$ ") é uma instância de fecho epistêmico. Observa-se que o conhecimento das duas premissas, sei que $P$ " e "sei que $P$ implica $n \tilde{a} o-Q$ ", implica no conhecimento da conclusão, a saber, "não sou um cérebro numa cuba"2. Porém, diriam alguns, hipóteses céticas não são facilmente falsificáveis. Logo, a aceitação do fecho implica em ceticismo! Com base nesse raciocínio, a sugestão de Dretske (op. cit.) é, como já foi dito, negar o fecho epistêmico, tomando-o como inválido.

\section{DEFININDO FECHO EPISTÊMICO}

${ }^{1}$ DE ALMEIDA, Cláudio. Closure, defeasibility and conclusive reasons. Acta Analytica, v. 22, n. 4, p. 301-319, dez. 2007. DRETSKE, Fred I. Epistemic operators. The Journal of Philosophy, v. 67, n. 24, p. 1007-1023, dez. 1970.

${ }^{2}$ Considerando, é claro, que o fecho seja aceito.

DIALEKTIKÉ, v. 1, novembro 2014, p. 109-133

Artigo submetido em fevereiro/2014 e aceito em junho/2014 
Suponha que você conheça que a seguinte proposição seja o caso:

$P_{1}$ : Estou lendo um artigo de epistemologia.

Observa-se que é possível deduzir um número infinito de proposições a partir de $P_{1}$. Como exemplo, considere as seguintes:

$P_{2}$ : Não sou um cérebro numa cuba.

$P_{3}$ : Não estou lendo um artigo de Física Teórica.

$P_{4}$ : Não estou jogando videogame.

$P_{5}$ : Não sou uma marionete do gênio maligno cartesiano.

$P_{6}$ : O mundo externo existe.

Não é difícil reconhecer - ao menos para pessoas racionais e em circunstâncias habituais $-P_{2}, P_{3}, P_{4}, P_{5}$ e $P_{6}$ como consequências lógicas de $P_{1}$. De outro modo, pode-se simplesmente dizer que estas cinco proposições são implicadas pela primeira. Formalmente, utilizando o símbolo “ $\rightarrow$ ” para representar a implicação, escreve-se $P_{1} \rightarrow P_{2}, P_{1} \rightarrow P_{3}$ e assim por diante. Assim, $P_{2} \rightarrow P_{n}$ pode ser traduzida como " $P_{2}$ implica $P_{n}$ ". Do mesmo modo, utilizando ' $K$ ' como símbolo para o operador de conhecimento, escreve-se ' $K P_{l}$ ' para dizer “eu conheço $P_{l}$ ", "o agente $S$ conhece $P_{l}$ ” ou simplesmente " $P_{l}$ é conhecida por alguém", entre outras. Assim, pode-se formalizar uma proposição como "eu sei que não estou lendo um artigo de Física Teórica", nesta maneira abreviada, simplesmente escrevendo $K P_{3}$-e assim por diante, para qualquer proposição ${ }^{3}$. Com isso estabelecido, a propriedade do fecho epistêmico pode ser expressa do seguinte modo:

(E-CLOS 1): Se $S$ conhece $P$ e conhece que $(P \rightarrow Q)$, então $S$ conhece $Q^{4}$.

Utilizando "\&" como símbolo para a conjunção, (E-CLOS 1) pode ser escrito,

\footnotetext{
${ }^{3}$ Quando necessário, também é possível utilizar subíndices especificadores de agentes: $K_{I} P_{1}, K_{S} P_{l}$, sendo ' $T$ ' e ' $S$ ' letras que representam o agente para quem o operador de conhecimento está sendo atribuído. De qualquer modo, é comum a omissão destes índices em casos em que a especificação é desnecessária.

${ }^{4}$ Optou-se por utilizar tal abreviação com o intuito de evitar complicações desnecessárias. Cada abreviação remete a um tipo específico de fecho epistêmico, e não outros. O termo 'E-CLOS' é uma abreviação do termo original inglês epistemic closure.
}

DIALEKTIKÉ, v. 1, novembro 2014, p. 109-133

Artigo submetido em fevereiro/2014 e aceito em junho/2014 
formalmente, do seguinte modo: $\left(K_{S} P \& K_{S}(P \rightarrow Q)\right) \rightarrow K_{S} Q$. Hendricks (2006, p. 60) observa que o princípio do fecho epistêmico, tal como expresso acima, é equivalente ao seguinte ${ }^{5}$ :

(E-CLOS 1'): Se $S$ conhece $P$, então, se $S$ conhece $(P \rightarrow Q)$, então $S$ conhece $Q^{6}$.

Formalmente, $K_{S}(P \rightarrow Q) \rightarrow\left(K_{S} P \rightarrow K_{S} Q\right)$, o famoso axioma $K$ da lógica epistêmica. Os princípios expostos acima atribuem ao operador de conhecimento a propriedade de "fecho sob implicação material", ou "fecho sob Modus Ponens"77. Segundo Kvanvig:

Um princípio de fecho é um princípio que afirma que uma dada categoria de objeto (tipicamente um conjunto) é fechado relativamente a alguma função, operação ou regra, de modo que a aplicação dessa operação em qualquer membro desse conjunto sempre nos levará a algo que já se encontra no conjunto. Considere, por exemplo, os números naturais e a operação de adição. Metaforicamente falando, podemos descrever a porta desse conjunto como fechada sob essa operação, dado que, sempre que adicionamos dois números naturais, isso nos leva a algo que já se encontra no conjunto ${ }^{8}$. (KVANVIG, 2006, p. 256).

No caso do fecho epistêmico, a propriedade definida por Kvanvig é supostamente satisfeita. Para compreender isso, considere $K$ não como um operador modal de conhecimento, mas como uma classe de conhecimento. Ou seja, entenda $K$ como "a classe das coisas que são conhecidas". Seja $S$ um agente e $P$ uma proposição qualquer tal que $S$ conhece $P$. Assim, afirmar " $S$ conhece $P$ ” é simplesmente afirmar que $P$ pertence a $K_{S}$ - isto é, à classe das proposições conhecidas por $S$. Suponha também que $(P \rightarrow Q) \square K_{S}$ - isto é, que $S$ conhece $(P \rightarrow Q)$. Agora, para expressar o fecho epistêmico, escreve-se:

Se $P \square K_{S} e(P \rightarrow Q) \square K_{S}$, então $Q \square K_{S}$.

\footnotetext{
${ }^{5}$ HENDRICKS, Vincent. Mainstream and formal epistemology. New York: Cambridge University Press, 2006. ${ }^{6}$ Em lógica epistêmica, este princípio também é conhecido como "fecho sob implicação material". A utilização deste termo pode ser encontrada em FAGIN, Ronald et al. Reasoning about knowledge. Massachusetts: The MIT Press, 2003.

${ }^{7} \mathrm{Na}$ lógica epistêmica clássica, "implicação lógica" e "implicação material” coincidem. As expressões "fecho sob implicação" e "fecho epistêmico" serão utilizadas para designar o princípio geral de que, "se o agente $S$ conhece $P$ e conhece $P \rightarrow Q$, então o agente $S$ conhece $Q$ '.

8 "A closure principle is a principle that claims that a certain category of object (typically a set) is closed relative to some function or operation or rule, in the sense that performing that operation on any member of the set always leads us to something already in the set. Consider, for example, the natural numbers and the operation of addition. Speaking metaphorically, we might describe the door to this set as being closed under this operation, since whenever we add two natural numbers, we are led to something already in the set."
}

DIALEKTIKÉ, v. 1, novembro 2014, p. 109-133

Artigo submetido em fevereiro/2014 e aceito em junho/2014 
Portanto, no fecho epistêmico, a função implicação, quando aplicada aos membros da classe das coisas conhecidas, gera elementos que já pertencem à referida classe.

Princípios como (E-CLOS 1) e (E-CLOS 1') são, na verdade, apenas exemplos particulares de fecho epistêmico. Alguns são mais fortes, outros mais fracos; há também aqueles que seriam supostamente tipos de fecho epistêmico, quando na verdade não o são. Os princípios acima, bastante discutidos em lógica epistêmica e epistemologia, também são os mais problemáticos em ambas as áreas. A eles são associados, em lógica epistêmica, o conhecido problema da "onisciência lógica" (HINTIKKA, 1962) e, em epistemologia, o problema da aceitação do ceticismo (DRETSKE, 1970) ${ }^{9}$.

\section{O ARGUMENTO CÉTICO POR MODUS TOLLENS}

Considere novamente as proposições da seção anterior. Agora, suponha que a proposição $P_{l}$ seja o caso; isto é, suponha que você esteja, neste momento, lendo um artigo de epistemologia. Dado isto, qualquer pessoa razoável diria que $P_{1}$ implica $P_{2}$, bem como $P_{5}$. Assim, se um agente, $S$, está lendo um artigo de epistemologia, então não é um cérebro numa cuba. Similarmente, se $S$ está lendo uma um artigo de epistemologia neste momento, então certamente não está sendo enganado pelo gênio maligno cartesiano. Deste modo, não há nada estranho em aceitar $P_{2}$ e $P_{5}$ como consequências lógicas de $P_{1}$. Considere agora estas duas instâncias do fecho epistêmico:

Instância 1: $\left(K_{V} P_{1} \& K_{V}\left(P_{1} \rightarrow P_{2}\right)\right) \rightarrow K_{V} P_{2}$. Informalmente:

Você sabe que está lendo um artigo de epistemologia.

Você também sabe que, se está lendo um artigo de epistemologia, então não é um cérebro numa cuba.

Logo - pelo fecho epistêmico - você sabe que não é um cérebro numa cuba.

Instância 2: $\left(K_{V} P_{1} \& K_{V}\left(P_{1} \rightarrow P_{5}\right)\right) \rightarrow K_{V} P_{5}$. Informalmente:

Você sabe que está lendo um artigo de epistemologia.

\footnotetext{
${ }^{9}$ HINTIKKA, Jaakko. Knowledge and Belief: an introduction to the logic of the two notions. New York: Cornell University Press, 1962.
}

DIALEKTIKÉ, v. 1, novembro 2014, p. 109-133

Artigo submetido em fevereiro/2014 e aceito em junho/2014 
Você também sabe que, se está lendo um artigo de epistemologia, então não é uma marionete do gênio maligno cartesiano.

Logo - pelo fecho epistêmico -, você sabe que não é uma marionete do gênio maligno cartesiano.

Proposições como $P_{2}$ e $P_{5}$ são conhecidas na literatura epistemológica como "hipóteses céticas" ou "possibilidades de erro céticas"10. Elas são chamadas assim justamente porque - ao menos à primeira vista - representam possibilidades que bloqueiam qualquer pretensão de conhecimento. Deste modo, quando você (verdadeiramente) diz "estou, neste exato momento, lendo um artigo de epistemologia", o cético pode atacar sua afirmação com "você está certo disso, considerando a possibilidade de que, em vez de ler um artigo de epistemologia, você seja uma marionete do gênio maligno cartesiano?". Deste modo, parece que, se as proposições "não sou um cérebro numa cuba" e "não sou uma marionete do gênio maligno cartesiano" são consequências lógicas de "estou, neste exato momento, lendo um artigo de epistemologia", então você também deveria saber que:

1. Você não é um cérebro numa cuba.

2. Você não é uma marionete do gênio maligno cartesiano.

Supondo que você conhece (i) que você está lendo um artigo de epistemologia e que também conhece (ii) as implicações $\left(P_{1} \rightarrow P_{2}\right)$ e $\left(P_{1} \rightarrow P_{5}\right)$, então você também deveria conhecer, ambas, $P_{2}$ e $P_{5}$. Isso é exatamente o que é requerido pelo fecho epistêmico. Assumindo que seja verdade que você sabe que está lendo um artigo de epistemologia e que, "estar lendo um artigo de epistemologia" implica "não ser um cérebro numa cuba", então você deve saber que não é um cérebro numa cuba (o mesmo vale para o caso do gênio maligno).

O cético pode agora fazer sua jogada. Ele pode gentilmente pedir que você considere a possibilidade de ser um cérebro em uma cuba - ou uma marionete do gênio maligno cartesiano. No atual estado de coisas, não há como você saber que você não é um cérebro numa cuba - diria o cético. Se você fosse um cérebro numa cuba, você não teria como saber de sua real situação - ao menos não sozinho, isto é, sem a ajuda de terceiros. Cérebros em cubas são

\footnotetext{
${ }^{10} \mathrm{Na}$ verdade, nas instâncias 1 e 2 apresentadas até agora, $P_{2}$ e $P_{5}$ estão representando as negações das hipóteses céticas "sou um cérebro numa cuba" e "sou uma marionete do gênio maligno cartesiano". Decidiu-se por não utilizar o símbolo lógico da negação, até agora, com o intuito de facilitar a compreensão dos exemplos. O símbolo “ $\neg "$ será introduzido em momento oportuno.
} 
estimulados por computadores poderosos a terem "as mesmas" sensações e percepções que as pessoas normais têm - simulando uma espécie de realidade virtual ${ }^{11}$. Deste modo, como dito antes, não há como você saber que não é um cérebro numa cuba.

Esta é uma premissa importante para o argumento cético. Ele, o cético, deseja que você a aceite como uma genuína possibilidade de erro. Assim, para ter conhecimento de qualquer coisa - diria ele - você teria de conhecer a falsidade da (s) hipótese (s) cética (s) associada (s) à proposição que você supostamente deveria conhecer. Logo, assumindo o fecho epistêmico, o cético dirá que você deveria conhecer as "proposições negação" das hipóteses céticas, pois as primeiras são consequências lógicas daquilo que você conhece. Colocando de outro modo, o cético concluirá seu argumento da seguinte forma - assumindo que você aceite o princípio do fecho epistêmico:

Premissa 1: Suponha que você saiba que está lendo um artigo de epistemologia.

Premissa 2: Suponha que você saiba que, se você está lendo um artigo de epistemologia, então você não é um cérebro numa cuba.

Premissa 3: Ora, acontece que você não sabe, e não tem como saber, que você não é um cérebro numa cuba.

Conclusão: Portanto, por Modus Tollens, você não sabe que está lendo um artigo de epistemologia. Para saber isto, você deveria conhecer a falsidade da hipótese cética em questão, o que não é o caso ${ }^{12}$.

O cético pode generalizar seu resultado pessimista. Seja $H$ qualquer hipótese cética. Seja o símbolo ' $\neg$ ' um representante formal para a negação. Assim, seja “ $\neg H$ ” uma representação simbólica para a negação da hipótese cética $H$. Em seguida, seja $P$ uma proposição qualquer conhecida por alguma pessoa. Feito isto, o "argumento geral da ignorância" ou Modus Tollens segue do seguinte modo:

1. $K P \quad$ Hipótese

\footnotetext{
${ }^{11}$ Para que o exemplo fique mais intuitivo, basta relembrar o filme "Matrix". Sem a ajuda de Morfeu, Neo não saberia que ele era prisioneiro da Matrix. As percepções que ela criava no cérebro de Neo eram tão similares às percepções de uma pessoa em condições normais que, sozinho, Neo não seria capaz de descobrir que havia sido enganado desde seu nascimento.

${ }^{12} \mathrm{~A}$ regra de inferência Modus Tollens é, ao mesmo tempo, muito simples e bastante utilizada em lógica proposicional. Ela diz que, se é verdade que $P$ implica $Q$ mas falso que $Q$, então $P$ também deve ser falsa.
}

DIALEKTIKÉ, v. 1, novembro 2014, p. 109-133

Artigo submetido em fevereiro/2014 e aceito em junho/2014 
2. $K(P \rightarrow \neg H)$

3. $(K P \& K(P \rightarrow \neg H)) \rightarrow K \neg H$

4. $\neg K \neg H$

5. $\neg(K P \& K(P \rightarrow \neg H)) 3,4$

6. $\neg K P \square \neg K(P \rightarrow \neg H) 5$

7. $\neg K P 2,6$
Hipótese

Fecho Epistêmico

Premissa cética

Modus Tollens

De Morgan

Silogismo disjuntivo

E assim o cético chega à sua conclusão pessimista: não se tem conhecimento nem mesmo de proposições simples como "estou lendo um artigo de epistemologia". Não se sabe dessas coisas porque as possibilidades de erro - ou hipóteses céticas - estão sempre presentes quando se afirma conhecer algo ou até mesmo atribuir conhecimento a outros. Algumas dessas possibilidades - como o cenário do cérebro numa cuba - não podem ser eliminadas: é impossível saber que elas são falsas. Se isso for o caso, o conhecimento parece algo impossível. Eis um grande problema para os epistemólogos, e tudo - como diria alguns - devido a aceitação de (E-CLOS 1).

Como se pode observar, o princípio (E-CLOS 1) desempenha um papel importante no argumento da ignorância. Não será possível, nele, obter $\neg K P$ a menos que você também aceite (E-CLOS 1). Uma possível solução para esse problema, portanto, seria simplesmente rejeitar (E-CLOS 1). Com isso, se bloquearia o argumento cético antes que ele atingisse o resultado pessimista expresso por $\neg K P$. Contudo, até mesmo um crítico do fecho - como o próprio Dretske - reconhece a plausibilidade de (E-CLOS 1), e que a ideia de abandoná-lo completamente não é muito popular entre os filósofos:

Feldman (1999) pensa que abandonar o fecho é "uma das ideias menos plausíveis a ganhar status na epistemologia esses últimos anos". DeRose (1995) acha-a intuitivamente "bizarra" ou "abominável". Fumerton (1987) pensa que a falha do fecho é uma "objeção devastante" e Bonjour (1987) um reductio ad absurdum de qualquer teoria que a implica ou a $\operatorname{adota}^{13}$. (DRETSKE, 2014a, p. 31).

Apesar disto, se existe algo pior do que abandonar o fecho, esse algo seria justamente abraçar o ceticismo. Se abandonar o fecho é a única maneira de escapar à conclusão gerada pelo

\footnotetext{
13 "Feldman (1999) thinks that abandoning closure is "one of the least plausible ideas to gain currency in epistemology in recent years." DeRose (1995) finds it "intuitively bizzare" or "abominable." Fumerton (1987) thinks the failure of closure is a "devastating objection" and BonJour (1987) a reductio ad absurdum to any theory that implies or embraces it."
}

DIALEKTIKÉ, v. 1, novembro 2014, p. 109-133

Artigo submetido em fevereiro/2014 e aceito em junho/2014 
argumento da ignorância, então a atitude de Dretske de rejeitar o fecho seria justificada. E é precisamente isso que Dretske pretende mostrar (2014a, p. 32):

[...] se fosse possível demonstrar que a rejeição do fecho não é apenas mais um meio de evitar o ceticismo (muitos filósofos concordariam com isso), mas a única forma de evitar o ceticismo, essa ideia teria um grande peso para filósofos que acham o ceticismo tão "bizarro" ou "abominável" quanto à rejeição do fecho ${ }^{14}$.

A posição de Dretske será analisada com mais cautela na seção abaixo.

\section{DRETSKE: RESPOSTA AOS CÉTICOS E AO FECHO EPISTÊMICO}

Em Epistemic Operators (1970), Dretske investiga os “degraus de penetrabilidade" de vários operadores - os epistêmicos estão entre eles. A propriedade de fecho é chamada de "penetrabilidade". Deste modo, ao dizer que um operador é "plenamente penetrante", afirmase que esse operador é fechado sob implicação lógica (em todos os casos). Similarmente, afirmar que algum operador é "não-penetrante" é simplesmente dizer que, até mesmo nos casos mais simples, o fecho não vale para esse operador.

Dretske apresenta um exemplo de operador não penetrante. Considere "é estranho que..." um operador. Agora, suponha que a seguinte proposição seja verdadeira:

$P_{7}$ : Ela perdeu o jogo.

Novamente, é possível deduzir um número infinito de proposições que são consequências lógicas de $P_{7}$. Exemplo:

$P_{8}:$ Alguém perdeu o jogo.

Não será difícil notar que $P_{7}$ implica logicamente $P_{8}$. No entanto, observe-se que não se pode deduzir a proposição "é estranho que alguém tenha perdido o jogo" da proposição "é estranho que $S$ tenha perdido o jogo". Ora, pode ser estranho que $S$, um indivíduo particular, tenha

\footnotetext{
14"“...] if a case could be made for the claim that a rejection of closure was not just a way to avoid skepticism (most philosophers would agree with this) but the only way to avoid skepticism, it should carry weight with philosophers who find skepticism as "bizarre" or "abominable" as the denial of closure."
}

DIALEKTIKÉ, v. 1, novembro 2014, p. 109-133

Artigo submetido em fevereiro/2014 e aceito em junho/2014 
perdido o jogo, considerando que ele estava tão preparado... Mas não é, de modo algum, estranho que alguém tenha perdido. Há sempre perdedores e ganhadores em jogos, isto é absolutamente normal. "É estranho que", portanto, é um exemplo que Dretske fornece de operador não-penetrante.

Por outro lado, para Dretske, "conhece que..." é um exemplo do que ele chama de “operador semi-penetrante”. Obviamente, esse operador não pode ser não-penetrante, pois seu degrau de penetrabilidade é maior do que o de operadores como "é estranho que...". Há um exemplo simples para ilustrar isso. Suponha que você conheça a seguinte proposição:

$P_{9}$ : Smith e Jones foram convidados para a festa.

Certamente, uma consequência lógica de $P_{9}$ seria:

$P_{10}:$ Smith foi convidado para a festa.

Parece aceitável que, se um agente conhece $P_{9}$, ele também conhece $P_{10}$. Deste modo, como um resultado trivial, "conhece que..." - que é um operador semi-penetrante - penetra mais profundamente do que operadores não-penetrantes. Contudo, o interesse de Dretske também é demonstrar que o operador "conhece que..." não é plenamente penetrante: há casos em que o fecho não vale para esse operador. Assim, argumenta Dretske, há casos que em (i) " $S$ conhece $P$ ", (ii) " $S$ conhece $(P \rightarrow Q)$ " mas (iii) " $S$ não conhece $Q$ ". Isso ocorre exatamente nos casos em que $Q$ é a negação de alguma hipótese cética - como, por exemplo, "eu não sou um cérebro numa cuba".

Até agora, observou-se que o fecho epistêmico dá espaço ao ceticismo através do argumento da ignorância. Como Dretske está ciente disso, sua estratégia é bloquear o referido argumento através da rejeição do princípio que o torna viável - o próprio fecho. Com a rejeição do fecho, o cético não obterá seu argumento, uma vez que não terá à disposição todas as premissas necessárias para sua demonstração. Entretanto, para uma plena compreensão do argumento de Dretske, é preciso entender o que ele quis dizer com o termo "consequências de contraste":

Suponha que asserimos que x é A. Considere algum predicado, 'B', que é incompatível com A, de modo que nada pode ser, ao mesmo tempo, A e B. Segue-se, portanto, do fato de que $\mathrm{x}$ é $\mathrm{A}$, que $\mathrm{x}$ não é $\mathrm{B}$. Além disso, se 
conjuntamos $\mathrm{B}$ com qualquer outro predicado $\mathrm{Q}$, seguir-se-á, do fato de que $\mathrm{x}$ é A, que x é não-(B e Q). Chamarei esse tipo de consequência de consequência de contraste, e estou interessado em um subconjunto dessa classe: pois acredito que as objeções céticas mais convincentes às nossas afirmações de conhecimento do dia a dia exploram um conjunto particular dessas consequências de contraste ${ }^{15}$. (DRETSKE, 1970, p. 1015).

Como exemplo, considere novamente a proposição $P_{l}$ : estou lendo um artigo de epistemologia. Para cada proposição - seguindo o raciocínio de Dretske - é possível associar uma outra que é consequência de contraste da primeira. Deste modo, é possível associar a $P_{l}$ a seguinte consequência de contraste:

$P_{4}$ : Não estou jogando videogame.

Agora, suponha que você saiba que $P_{l}$ seja o caso. Suponha também que você saiba que, se está lendo um artigo de epistemologia, então você não está jogando videogame. Conclui-se disso, pelo fecho epistêmico, que você sabe que não está jogando videogame.

Ao observar de perto este exemplo, tudo parece estar em ordem. Na verdade, está. Para Dretske, ao se considerar a proposição "não estou jogando videogame", parece que se está pressupondo o "estar jogando videogame" como uma possibilidade relevante. Porém, considere agora um argumento cético que contém uma consequência de contraste estranha:

\section{Argumento cético}

Sejam as proposições:

$P$ : A parede é vermelha.

$Q$ : A parede é branca.

$R$ : A parede está sendo engenhosamente iluminada para parecer vermelha.

Como se pode ver, $P$ implica $n \tilde{a} o-Q$ e $n \tilde{a} o-R$ e, portanto, implica $n \tilde{a} o-(Q$ e $R)$. Suponha que

\footnotetext{
15 "Suppose we assert that $x$ is $A$. Consider some predicate, ' $B$ ', which is incompatible with $A$, such that nothing can be both $A$ and $B$. It then follows from the fact that $x$ is $A$ that $x$ is not $B$. Furthermore, if we conjoin $B$ with any other predicate $Q$, it follows from the fact that $x$ is $A$ that $x$ is not- $(B$ and $Q)$. I shall call this type of consequence a contrast consequence, and I'm interested in a particular subset of these: for I believe the most telling skeptical objections to our ordinary knowledge claims exploit a particular set of these contrast consequences."
}

DIALEKTIKÉ, v. 1, novembro 2014, p. 109-133

Artigo submetido em fevereiro/2014 e aceito em junho/2014 
você conhece $P$ e também estas implicações. Assim, suponha que você conhece tanto $P$ quanto $P$ implica $n \tilde{a} o-(Q$ e $R)$. Pelo fecho epistêmico, você também deve conhecer não- $(Q$ e $R)$. Mas você realmente sabe que $n \tilde{a} o-(Q e R)$ é o caso? Ora, considerando que você não tem como saber $n \tilde{a} o-(Q$ e $R)$ - porque não tem como saber $n \tilde{a} o-R$ - conclui-se que você não conhece $P$, a saber, que a parede é vermelha ${ }^{16}$.

Quando se observa uma parede vermelha, geralmente não se considera a possibilidade de ser enganado por falsa iluminação ou, talvez, demônios malignos. Em outras palavras: estas não são consideradas possibilidades relevantes.

No entanto, ao se prestar mais atenção aos dois casos, observa-se que essas possibilidades remotas não deixam de ser possibilidades. Deste modo, a pergunta "E se...?" permanece a incomodar. É claro que se pode insistir: "mas aquelas são zebras, eu tenho certeza!” Porém, o cético pode replicar: "e se elas fossem, na realidade, mulas engenhosamente disfarçadas pelas autoridades do zoológico? Você está certo, sem qualquer sombra de dúvida, que isso não seja o caso?"

Dretske vê uma saída para esse problema. Ele argumenta que, sem qualquer dúvida, você conhece que "a parede é vermelha" e que "aqueles animais são zebras". Para que você conheça as respectivas proposições, não é necessário que também conheça a falsidade das hipóteses céticas associadas a elas, pois o operador de conhecimento não penetra nas consequências de contraste comumente apresentadas pelo cético. Em outras palavras, o fecho epistêmico não vale nos casos em que a consequência lógica do conhecimento de alguém é a negação de alguma hipótese cética. Assim, se ele não vale, você não é obrigado a conhecer todas as consequências lógicas daquilo que você conhece. No argumento acima, que envolve a negação de uma hipótese cética como consequência de contraste, mesmo ao se assumir que você conheça $P$, não se pode requerer de você que também conheça a falsidade de $(Q e R)$. Logo, sem qualquer receio, você pode dizer: "eu não sei se $(Q$ e $R)$ ou não- $(Q$ e $R)$, e daí?" Enfim, seu conhecimento de proposições não-céticas está seguro novamente.

Depois de mais de trinta anos (2014a e 2014b), a posição de Dretske com relação ao fecho epistêmico continua a mesma. Na verdade, sua postura sobre o fecho é uma consequência

\footnotetext{
${ }^{16}$ É importante observar que, de uma perspectiva mais rigorosa, a proposição "não- $(Q e$ $R)$ " não é uma consequência lógica direta de $P$, não- $Q$ e não- $R$. O argumento de Dretske está, portanto, incompleto. Uma demonstração rigorosa deste argumento seria mais ou menos assim: para redução ao absurdo, pode-se supor que $(Q e R)$ seja verdadeira. Como $(Q e R)$ é uma conjunção, infere-se $Q$. Porém, sabe-se tanto que $P$ é o caso como também que $P$ implica não- $Q$. Assim, por eliminação da implicação (ou Modus Ponens), infere-se não- $Q$. Mas aí, encontra-se uma contradição entre $Q$ e não- $Q$. Assim, a hipótese $(Q$ e $R)$ deve ser falsa. Portanto, por redução ao absurdo, não- $(Q$ e $R)$ deve ser verdadeira.
}

DIALEKTIKÉ, v. 1, novembro 2014, p. 109-133

Artigo submetido em fevereiro/2014 e aceito em junho/2014 
necessária de sua concepção acerca da noção de conhecimento (DRETSKE, 1971) ${ }^{17}$. Em sua opinião, conhecer uma proposição $P$, por exemplo, é possuir razões conclusivas para $P$. Dretske define o conceito de razões conclusivas contrafactualmente:

$C R$ : " $R$ é uma razão conclusiva para $P$ " é equivalente a " $R$ não seria o caso se $P$ não fosse o caso" (ou: "se $P$ não fosse o caso, $R$ também não seria o caso") ${ }^{18}$.

Agora, considere a proposição $P_{1}$ mais uma vez. Se você conhece $P_{1}$, então - segundo Dretske - você tem razões conclusivas para $P_{1}$. Seja $R$ uma abreviação para esse conjunto de razões conclusivas ${ }^{19}$. Assim, se você conhece $P_{1}$, é porque você possui $R$. A condição $C R$ diz que, se $P_{1}$ fosse falsa, você não teria $R$. Suponha, portanto, que $P_{1}$ seja verdadeira - isto é, que você realmente esteja lendo um artigo de epistemologia. E agora? Você possui razões conclusivas para isto? Para alcançar o resultado desejado, deve-se verificar se a proposição "o agente $S$ [você] está agora lendo um artigo de epistemologia" satisfaz a condição $C R$ : se $P_{1}$ fosse falsa, o agente $S$ não teria $R$. As evidências para $P_{1}$ são muitas. Você pode ver o papel bem à sua frente. Você também pode ver as letras, compreender as palavras utilizadas pelo autor etc. Além disso, você pode compreender todos os conceitos relevantes, seus argumentos, razões etc. Se o artigo for impresso, também é possível tocá-lo com suas mãos. Ora, se você não estivesse lendo este artigo, isto é, se $P_{l}$ fosse falsa, então você não teria todas essas evidências para a proposição $P_{1}$. Portanto, se $P_{1}$ fosse falsa, você não teria $R$. Como se pode ver, a condição $C R$ é satisfeita. Você sabe que está lendo um artigo de epistemologia. Mas o que dizer de proposições que envolvem hipóteses céticas? Não é difícil notar que você nunca terá razões conclusivas para proposições como "não sou um cérebro numa cuba" ou "não sou uma marionete do gênio maligno cartesiano".

Para isso, considere a proposição $P_{2}$. Suas razões para acreditar em $P_{2}$ também são muitas. Neste exato momento, você está lendo um artigo em epistemologia (cérebros não leem). Além disso, você está segurando este artigo com suas próprias mãos (as mesmas mãos que você pode sentir); você pode ver o papel, tocá-lo, sentir o seu cheiro etc. Ora, cérebros não fazem todas estas coisas! A condição $C R$ diz que, se $P_{2}$ fosse falsa, você não teria todas as evidências que você tem para acreditar na proposição $P_{2}$. Assim, $C R$ diz que, se você fosse um cérebro

17 ${ }^{18}$ CR é uma abreviação para "conclusive reasons".

${ }^{19} R$ pode ser pensado como o conjunto de todas as evidências que apoiam a verdade da proposição em questão.

DIALEKTIKÉ, v. 1, novembro 2014, p. 109-133

Artigo submetido em fevereiro/2014 e aceito em junho/2014 
numa cuba, você não veria suas mãos, este artigo e assim por diante.

Mas isto não é verdade. O cientista maluco que aprisionou o seu cérebro teria o poder de enganá-lo acerca de quase tudo. Ele poderia fazer o seu cérebro pensar que é uma pessoa de verdade (com mãos, cabeça etc.) quando de fato não o é. Se essa situação fosse satisfeita, você teria $R$ mesmo que $P_{2}$ fosse falsa. Mas isso contradiz a condição $C R$. Logo, você não tem razões conclusivas para $P_{2}$ e, portanto, não sabe que $P_{2}$ é o caso. $\mathrm{O}$ fecho epistêmico, neste caso particular, deve ser falso porque:

1. Você pode possuir razões conclusivas para $P_{1}$;

2. você pode possuir razões conclusivas para $P_{1} \rightarrow P_{2}$;

3. você não pode possuir razões conclusivas para $P_{2}$.

Para completar a tarefa de invalidação do fecho, Dretske fará uso de suas famosas "proposições heavyweight". Essas proposições são de grande importância para Dretske, pois elas são os pilares de sua teoria contra o fecho. Hawthorne, adversário de Dretske, as define do seguinte modo:

Seja $P$ uma "proposição heavyweight" exatamente quando todos possuímos uma inclinação forte para pensar que $P$ não seja o tipo de coisa que se possa conhecer apenas através do exercício da razão, e também que $P$ não seja o tipo de coisa que se possa conhecer pela utilização das faculdades perceptuais (mesmo quando estas últimas sejam auxiliadas pela razão) ${ }^{20}$. (HAWTHORNE, 2014, p. 47).

Então, grosso modo, uma proposição heavyweight é aquela que não é facilmente cognoscível. Observa-se, no entanto, que a definição não é precisa. Quando uma proposição deve ser considerada heavyweight? Eis uma questão difícil. Todavia, ainda é possível apresentar algumas proposições que seriam, provavelmente, consideradas heavyweight. Tome-se, como exemplo, a proposição $P_{2}$. A proposição "não sou um cérebro numa cuba" é do tipo que pode ser conhecida pela percepção? Muitas pessoas diriam que não. Filosoficamente falando, a proposição em questão não é do tipo que pode ser conhecida apenas com base em nossas próprias percepções sensoriais. Mas será que, por acaso, não existe um outro meio de descobrir que $P_{2}$ é verdadeira?

\footnotetext{
20 "Let $P$ be a "heavyweight proposition" just in case we all have some strong inclination to think that $P$ is not the sort of thing that one can know by the exercise of reason alone and also that $P$ is not the sort of thing that one can know by use of one's perceptual faculties (even aided by reason)."
}

DIALEKTIKÉ, v. 1, novembro 2014, p. 109-133

Artigo submetido em fevereiro/2014 e aceito em junho/2014 
Alguns diriam que sim, outros diriam que não. $O$ fato é que $P_{2}$ não é uma proposição fácil de provar - filosoficamente, pelo menos. Se por acaso o fosse, o desafio cético talvez não existisse. Infelizmente, é sabido que o desafio cético existe e continua a exigir atenção da epistemologia contemporânea. $\mathrm{O}$ ceticismo não é tão fácil de refutar.

\section{O EFEITO DAS PROPOSIÇÕES HEAVYWEIGHT}

Um detalhe interessante sobre as proposições heavyweight é justamente o de que seu número é infinito. Através de um simples raciocínio, o seguinte resultado pode ser obtido:

Para cada proposição, $P$, existe uma outra proposição, $Q$, de modo que $Q$ pode ser associada a $P$ como uma consequência lógica de $P$, e $Q$ é uma proposição heavyweight.

Exemplo:

- $P: S$ está vivo (proposição verdadeira escolhida arbitrariamente);

- $Q$ : $S$ não está enterrado no cemitério local;

- $Q_{1}: S$ não está no "céu";

- $Q_{2}$ : $S$ não está no Hades;

$\bullet \ldots$

- $\mathrm{Q}_{\infty}$.

Já foi observado que a percepção não é uma fonte adequada de conhecimento de proposições heavyweight. Seria possível, talvez, conhecê-las de alguma outra forma. Infelizmente, o exemplo da seção anterior apoia a posição de Dretske, pois todos os meios de conhecer proposições heavyweight "ou falham em alcançar essas implicações heavyweight ou geram suas próprias implicações heavyweight" (DRETSKE, 2014a, p. 35). Outros meios de conhecer $Q$ seriam através do testemunho ou da memória, ou algo parecido. Infelizmente, é possível gerar implicações heavyweight para cada fonte de conhecimento que se possa pensar. Em contrapartida, os defensores do fecho não deixam de apresentar seus argumentos. A próxima seção expõe alguns deles.

\section{RESPOSTA DE HAWTHORNE A DRETSKE}

DIALEKTIKÉ, v. 1, novembro 2014, p. 109-133

Artigo submetido em fevereiro/2014 e aceito em junho/2014 
Baseando-se na ideia de Williamson (2000, p. 117) de que a dedução é um modo de expandir o conhecimento, Hawthorne (2014, p. 43) apresenta uma versão atraente de fecho:

(E-CLOS-H): Se $S$ conhece $P$ e deduz competentemente $Q$ de $P$, vindo a acreditar em $Q$ enquanto retém o conhecimento de $P$, então $S$ vem a conhecer $Q$.

Apesar de (E-CLOS-H) não ser o alvo original de Dretske, todos os seus argumentos contra (E$C L O S$ 1) também se aplicam a $(E-C L O S H)$. Como se sabe, as pessoas não saem por aí acreditando seriamente que são cérebros em cubas ou marionetes do gênio maligno cartesiano. Isso ocorre porque elas sabem, por exemplo, que elas possuem corpos, e que "possuir um corpo" implica em "não ser um cérebro numa cuba". Deste modo: (i) elas conhecem $P$ (elas têm corpos); (ii) elas sabem que $P$ (ter um corpo) implica $Q$ (não ser um cérebro numa cuba); (iii) elas acreditam em $Q$ (elas não são cérebros em cubas), enquanto retêm conhecimento das premissas (i) e (ii); (iv) elas vêm a saber que não são cérebros em cubas.

Alguém pode se perguntar se há alguma coisa errada com esse raciocínio. Hawthorne diria que não, já Dretske diria que sim. Segundo este último, a conclusão do argumento é a negação de uma hipótese cética; isto é, uma proposição heavyweight ainda aparece como conclusão do referido argumento.

No que se segue, serão apresentados os argumentos de Hawthorne contra a posição de Dretske (juntamente com algumas objeções a Hawthorne), com foco central nas proposições heavyweight. As principais objeções contra Hawthorne, contudo, ficarão para a próxima seção, em que as intuições de McBride (2009) sobre assunto serão analisadas ${ }^{21}$. Por enquanto, a atenção será direcionada para um argumento muito simples, baseado no "princípio da equivalência":

(EQP) Princípio da equivalência: Se $S$ conhece a priori que $P$ é equivalente a $Q$, conhece $P$ e deduz $Q$ de $P$, retendo o conhecimento de $P$, então $S$ conhece $Q^{22}$.

Argumento de Hawthorne. Dretske está comprometido com a rejeição da distribuição. Para

\footnotetext{
${ }^{21}$ MCBRIDE, Mark. Is knowledge closed under known entailment? The strange case of Hawthorne's "heavyweight conjuncts" (and other strange cases). Theoria, v. 75, n. 2, p. 117-128, mai. 2009.

${ }^{22}(\mathrm{EQP})$ é uma abreviação para equivalence principle.
}

DIALEKTIKÉ, v. 1, novembro 2014, p. 109-133

Artigo submetido em fevereiro/2014 e aceito em junho/2014 
isso, suponha que um agente qualquer, $S$, conhece $P$ : “A taça está cheia de vinho". Seja $Q$ a seguinte proposição: "A taça está cheia de um líquido colorido artificialmente para parecer com o vinho." Seguindo o raciocínio, a proposição $P$ é “equivalente a priori" a " $P$ e $n a \tilde{o}-Q$ ". Daí, pelo princípio da equivalência, $S$ conhece a respectiva conjunção. Agora, pelo princípio da distribuição, se $S$ conhece a referida conjunção, $S$ conhece os constituintes dela. Isto é, se $S$ conhece " $P$ e não- $Q$ ", $S$ também deve conhecer não- $Q$. Porém, segundo Dretske, $S$ não pode saber isto. Conclusão: se a posição de Dretske for aceita, o princípio da distribuição deve ser rejeitado.

Observação crítica. Primeiramente, os insights iniciais de Dretske acerca da distribuição são favoráveis, não o contrário (DRETSKE, 1970, p. 1009). Em Epistemic Operators, Dretske aceita o princípio da distribuição. Além disso, se for insistido que a abordagem das razões conclusivas força a rejeição do princípio da distribuição, então será possível fornecer uma implementação não ad hoc da definição de razões conclusivas que será capaz de bloquear a conjunção " $P$ e não- $Q$ ” (McBRIDE, 2009), impedindo o argumento de Hawthorne através da rejeição de premissas ${ }^{23}$. O resultado é o seguinte: o desafio proposto por Dretske ainda não foi solucionado.

Entretanto, Hawthorne oferece outros argumentos contra a posição de Dretske. Como foi visto, a noção de proposição heavyweight é central na visão crítica de Dretske. Deste modo, se ela estiver equivocada, a "estratégia heavyweight" pode levar a lugar nenhum. Hawthorne tenta estabelecer casos em que: (i) um agente $S$ tem razões conclusivas para uma proposição manifestamente heavyweight; (ii) um agente $S$ carece de razões conclusivas para $Q$, sendo $Q$ uma proposição não-heavyweight. As próximas três seções mostram como ele tenta alcançar estes dois resultados.

7 PROPOSIÇÕES MANIFESTAMENTE HEAVYWEIGHT COM RAZÕES CONCLUSIVAS

\subsection{CASO DE HAWTHORNE NÚMERO 1 (O CASO DA DOR DE CABEÇA)}

Considere novamente a proposição $P_{2}$. De acordo com Dretske, não há como saber

\footnotetext{
${ }^{23}$ No presente caso, com a rejeição da premissa de que $S$ conhece a conjunção entre $P$ e $n a \tilde{a}-Q$.

DIALEKTIKÉ, v. 1, novembro 2014, p. 109-133

Artigo submetido em fevereiro/2014 e aceito em junho/2014
} 
isto, pois $P_{2}$ carece de razões conclusivas. Isto é: se $P_{2}$ fosse falsa, ainda se teria $R$ (um conjunto de evidências de apoio para $P_{2}$ ). Agora, considere a proposição $Q$ : "eu tenho uma dor de cabeça e eu não sou um cérebro numa cuba". Parece é possível encontrar conclusivas para $Q$. Considerando que o conjunto de evidências para $P$ inclui a dor de cabeça, observa-se que: se $Q$ fosse falsa, não haveria $R$. Contudo, $Q$ é uma proposição heavyweight. Logo, é possível se ter razões conclusivas para uma proposição heavyweight. Se isto estiver correto, a posição de Dretske possui algum defeito. Dada a possibilidade de se conhecer proposições heavyweight, não será necessário restringir o fecho apenas às proposições light e middleweight.

\subsection{CASO DE HAWTHORNE NÚMERO 2 (O CASO “PARECE UM PÁSSARO”)}

Suponha que você esteja num zoológico e esteja vendo um pássaro voando em uma gaiola próxima a você. Com base em suas evidências perceptuais, você conclui que existe um pássaro na gaiola. "Neste momento - você raciocina -, o pássaro que eu vejo não é um objeto inanimado, engenhosamente disfarçado para parecer com um pássaro de verdade." É evidente que esta proposição é heavyweight. Seja $Q$ a abreviação para esta proposição. Agora, há um detalhe importante: se alguém fosse fazer um objeto inanimado parecer com um objeto animado, esse alguém escolheria algo muito mais fácil de imitar; escolheria, por exemplo, fazer uma imitação de tartaruga. Assim, nos mundos mais próximos em que há um objeto inanimado na gaiola (engenhosamente disfarçado para enganá-lo), não há qualquer coisa parecida com um pássaro. Ou seja, nos mundos mais próximos em que existe um objeto inanimado engenhosamente disfarçado, tal objeto não pareceria com um pássaro, e sim com uma tartaruga - que, plausivelmente, seria mais fácil de imitar. Mas repare que: "se $Q$ fosse falsa, você não teria $R$ "; isto é, se não existisse um pássaro na gaiola, você não o veria. Logo, neste caso, você tem razões conclusivas para $Q$ - que é heavyweight.

\subsection{CASO DE HAWTHORNE NÚMERO 3 (O “CASO DO BISCOITO”)}

Suponha uma situação em que há um biscoito diante de você. Devido a suas experiências perceptuais, você constrói a crença de que existe um objeto real que está, grosso modo, a um metro e meio de distância de você ${ }^{24}$. A proposição "existe um objeto real que está

\footnotetext{
${ }^{24} \mathrm{O}$ termo original em inglês é mind-independent object. Com isso, o autor sugere um objeto que possui realidade objetiva, isto é, existe fora da mente do agente em questão; em outras palavras, não precisa do agente para existir,
}

DIALEKTIKÉ, v. 1, novembro 2014, p. 109-133

Artigo submetido em fevereiro/2014 e aceito em junho/2014 
a um metro e meio de distância de mim" pode ser caracterizada como heavyweight. Novamente, seja $Q$ a abreviação para esta proposição. Como no caso anterior, se $Q$ fosse falsa, você não teria $R$ : nos mundos mais próximos, se não houvesse um objeto real a um metro e meio de você, você não acreditaria na existência de um objeto real a um metro e meio de você - aquele lugar não estaria sendo ocupado por qualquer coisa e, por conta disso, você não acreditaria haver qualquer objeto ali. Logo, mais uma vez, você tem razões conclusivas para $Q$ - que é heavyweight. Deve-se notar que, se os casos 1, 2 e 3 estiverem corretos, a tese defendida por Hawthorne constitui uma objeção séria à teoria das proposições heavyweight.

\section{IMPLICAÇÕES DOS CASOS DE HAWTHORNE}

Como se pode observar, os três casos acima pretendem demonstrar que é possível possuir razões conclusivas para proposições heavyweight. Se isso for verdade, então não há nada de errado com o fecho epistêmico. Ou seja, se é possível ter razões conclusivas para proposições heavyweight - ou, em outras palavras, se proposições heavyweight são cognoscíveis -, então o fecho epistêmico não está restrito apenas a proposições lightweight e middleweight. A abordagem de Dretske é irrelevante.

No entanto, o argumento de Hawthorne parece estar incompleto. A menos que ele possa provar que se pode ter razões conclusivas para todas as proposições heavyweight, seu argumento não funcionará como desejado. Pois, se acontecer de existir pelo menos uma proposição que seja, ao mesmo tempo, heavyweight e incognoscível, isso será suficiente para manter Dretske no jogo. Isso ocorre porque a tese de Dretske é particular e negativa. Ele pensa o fecho como sendo inválido. Para sustentar sua posição, ele precisa apenas encontrar algum caso particular em que o fecho não seja aplicável. Por outro lado, Hawthorne deve demonstrar que toda proposição supostamente heavyweight de Dretske não é incognoscível, já que é possível encontrar razões conclusivas para cada uma delas. Logo, mesmo se os três casos apresentados por Hawthorne estiverem corretos, ainda assim eles serão todos particulares. Porém, considerando que seu argumento requer um resultado geral, as premissas apresentadas (os três casos em que proposições heavyweight são cognoscíveis) não poderão garantir a conclusão.

Em outras palavras, o argumento oferecido por Hawthorne não garante a generalidade

não é uma criação de sua mente.

DIALEKTIKÉ, v. 1, novembro 2014, p. 109-133

Artigo submetido em fevereiro/2014 e aceito em junho/2014 
pretendida para a rejeição completa da teoria de Dretske. Mesmo que sejam listados inúmeros casos particulares em que proposições heavyweight são cognoscíveis, ainda assim será possível encontrar uma proposição heavyweight incognoscível. Hawthorne deveria fornecer algum mecanismo que garantisse a generalidade de que seu argumento necessita para funcionar. Porém, ele não faz isso. Assim, a posição - correta ou incorreta - de Dretske continua firme. O conhecido "desafio de Dretske" não foi satisfatoriamente solucionado por Hawthorne. Apesar disso, Hawthorne insiste na segunda parte de seu argumento; segundo ele, algumas proposições não-manifestamente heavyweight carecem de razões conclusivas.

\section{PROPOSIÇÕES NÃO-MANIFESTAMENTE HEAVYWEIGHT SEM RAZÕES CONCLUSIVAS}

Para Hawthorne (2014, p. 47), em algumas circunstâncias, carece-se de razões conclusivas para proposições não-heavyweight. Se isso puder ser estabelecido, ficará demonstrado que toda a iniciativa da abordagem das proposições heavyweight não traz qualquer resultado relevante para a discussão do fecho - assim pensa Hawthorne. O raciocínio implícito nesta estratégia é bastante simples:

(1) A abordagem heavyweight “...foi projetada para fornecer a conclusão de que é possível conhecer proposições comuns e suas consequências "não manifestamente heavyweight", enquanto se permanece ignorante de suas consequências manifestamente heavyweight"; (HAWTHORNE, 2014, p. 49).

(2) é possível ter razões conclusivas para proposições heavyweight;

(3) carece-se de razões conclusivas para algumas proposições não-heavyweight;

(4) a "abordagem heavyweight" não fornece o resultado que ela mesmo estabeleceu em suas metas;

(5) logo, a “abordagem heavyweight" está errada.

Até agora, seguiu-se Hawthorne e tomou-se (1) como premissa. Os casos 1, 2 e 3 de Hawthorne - sobre a cognoscibilidade de proposições heavyweight - "estabeleceram" (2). Agora, para terminar, (3) é requerido ${ }^{25}$. Para estabelecer (3), Hawthorne utiliza o "caso do salmão".

\footnotetext{
${ }^{25} \mathrm{O}$ passo (4) segue dos passos (2) e (3), na medida em que a abordagem inicial de Dretske pretende estabelecer duas coisas: (i) não é possível encontrar razões conclusivas para proposições heavyweight e (ii), sempre temos
}

DIALEKTIKÉ, v. 1, novembro 2014, p. 109-133

Artigo submetido em fevereiro/2014 e aceito em junho/2014 


\subsection{CASO DE HAWTHORNE NÚMERO 4 (O “CASO DO SALMÃO”)}

Suponha que você tenha comido na janta uma certa quantidade de salmão. Já que você não é guloso, você forma a crença de que comeu menos de 14 quilos de salmão. Seja $Q$ a abreviação para a seguinte proposição: "eu comi menos do que 14 quilos de salmão no jantar". Assim, depois do jantar, você forma a crença de que $Q$ é o caso. Em princípio, não há qualquer coisa anormal com a proposição $Q$, de modo que $Q$ não deve ser considerada heavyweight. Considere $Q$, portanto, como uma proposição comum - uma proposição não-heavyweight. Deste modo, após o jantar, você forma uma crença em uma proposição não-heavyweight. Porém, suponha, adicionalmente, que o ato de comer mais do que 14 quilos de salmão o induziria a ter alucinações sobre haver comido menos de 1 quilo de salmão. Agora, lembre-se da definição de razões conclusivas: "Se $Q$ não fosse o caso, $R$ não seria o caso."

Suponha, por hipótese, que a proposição "eu comi menos do que 14 quilos de salmão no jantar" seja falsa. Logo, você comeu 14 quilos ou mais de salmão no jantar. Mas isso causaria alucinações em você, de modo que você continuaria acreditando que comeu menos do que 14 quilos de salmão no jantar. Logo, se $Q$ fosse falsa, $R$ ainda seria o caso! Conclusão: apesar de $Q$ não ser heavyweight, você carece de razões conclusivas para $Q$.

\section{RESPOSTA DE McBRIDE A HAWTHORNE}

Felizmente, para Dretske, é possível fazer uma implementação não ad hoc na definição de razões conclusivas. Tal implementação é fornecida por McBride (2009). Segundo ele, a tese de Dretske deveria ser implementada com a seguinte condição (MCBRIDE, 2009, p. 123):

(SUPP): se $P$ é uma proposição conjuntiva, $R$ não seria verdadeira caso cada um dos conjuntos de $P$, tomados separadamente, não o fosse ${ }^{26}$.

Pode-se questionar se esta condição é apenas ad hoc. No entanto, McBride mostra que ela não o é. Suponha, por exemplo, que você tenha uma dor de cabeça. Dado isto, está claro que você

razões conclusivas para proposições não-heavyweight. Se ambas as teses estiverem erradas, diria Hawthorne, a abordagem das proposições heavyweight não fornece o resultado esperado.

${ }^{26} \mathrm{Ou}$ seja, se $P$ é uma proposição do tipo $(A \& B)$, sendo $A$ e $B$ também proposições, $R$ não seria verdadeira caso $A$ ou $B$ não o fosse; para que $R$ seja verdadeira, $A$ e $B$ devem, igualmente, ser verdadeiras.

DIALEKTIKÉ, v. 1, novembro 2014, p. 109-133

Artigo submetido em fevereiro/2014 e aceito em junho/2014 
tem razões conclusivas para a proposição:

$P$ : Eu tenho uma dor de cabeça.

Suas razões para acreditar nesta proposição incluem sua própria dor de cabeça. Agora, se (SUPP) não fosse aceita, como consequência, você teria razões conclusivas para a seguinte proposição:

$Q$ : Eu tenho uma dor de cabeça e eu possuo todos os meus membros.

Isso porque os mundos em que é falso que você tem uma dor de cabeça são mais próximos daqueles em que você não possui algum membro. Precisamente nestes primeiros mundos, a condição $C R$ é satisfeita: se $Q$ fosse falsa, eu não teria $R$.

Isto é, se você não estivesse com dor de cabeça, você não teria razões para acreditar que estivesse. Deste modo, se (SUPP) não for aceita, você pode ter razões conclusivas para $Q$ simplesmente se baseando no fato de que você tem razões conclusivas para $P$, e isto não é verdade.

Por esta razão, sustenta McBride, deve-se a admitir ( $S U P P$ ) como condição necessária à definição de razões conclusivas. Com (SUPP), é fácil compreender porque o caso número 1 de Hawthorne não apresenta qualquer ameaça à teoria das razões conclusivas.

\subsection{RESPOSTA DE MCBRIDE AO ‘CASO 1’ DE HAWTHORNE - UTILIZANDO (SUPP)}

McBride apresenta (2009, p.124), grosso modo, o seguinte argumento:

Seja $S$ um agente qualquer. O agente $S$ conhece a proposição $P$ : "eu tenho uma dor de cabeça e eu não sou uma cérebro numa cuba" somente $\mathrm{se}^{27}$ :

(1). $S$ possui razões conclusivas para "eu tenho uma dor de cabeça";

(2). $S$ possui razões conclusivas para "eu não sou um cérebro numa cuba".

\footnotetext{
${ }^{27} \mathrm{O}$ pronome "eu" se refere ao agente em questão, isto é, a $S$.
} 
Ora, $S$ carece de razões conclusivas para "eu não sou um cérebro numa cuba". Logo, por $(S U P P), S$ carece de razões conclusivas para a proposição "eu tenho uma dor de cabeça e eu não sou um cérebro numa cuba". Mas a proposição $P$ - que é uma conjunção - é heavyweight. Conclusão: $S$ carece de razões conclusivas para uma proposição heavyweight - isto é, para $P$ que, como foi visto, é heavyweight.

Segundo McBride, os casos 2 e 3 têm uma solução simples. Desta vez, o apelo a $(S U P P)$ nem mesmo é necessário. Isso acontece porque, como McBride coloca, ambos os casos não são instâncias genuínas de proposições heavyweight.

\subsection{RESPOSTA DE MCBRIDE AO ‘CASO 2’ DE HAWTHORNE - SEM (SUPP)}

Antes de tudo, McBride (2009, p. 124) observa que a proposição "neste momento, o pássaro que eu vejo não é um objeto inanimado, engenhosamente disfarçado para parecer como um pássaro de verdade" não é heavyweight. A resposta é simples: Hawthorne assumiu que, nos mundos mais próximos em que há de fato uma imitação, tal imitação não seria de um pássaro, mas de algo muito mais fácil de imitar - uma tartaruga, talvez. Deste modo, a possibilidade de um objeto inanimado que seja parecido com um pássaro é muito remota para ser considerada relevante. Se isso for o caso, é possível conhecer a proposição em questão apenas com base na percepção do pássaro voando pela gaiola. Porém - deve-se lembrar - se isto é possível, então a referida proposição não será heavyweight. Proposições heavyweight não podem ser conhecidas apenas com base em percepções.

Por outro lado, se a possibilidade de um objeto parecido com um pássaro for considerada seriamente, os mundos mais próximos permitirão objetos inanimados parecidos com pássaros. Daí, se esta possibilidade for levada a sério, a proposição em questão deverá contar como heavyweight. Nestes mundos, um agente acreditaria na respectiva proposição ainda que ela fosse falsa. Em outras palavras, o agente em questão careceria de razões conclusivas para a referida proposição.

\subsection{RESPOSTA DE MCBRIDE AO ‘CASO 3’ DE HAWTHORNE - SEM (SUPP)}

Novamente, neste caso, McBride (op. cit.) mostra que Hawthorne falha em fornecer uma proposição genuinamente heavyweight. Isto é, "existe um objeto real que está a um metro e meio de distância de mim" não pode ser caracterizada como heavyweight. Os mundos mais 
próximos em que a respectiva proposição é falsa são mundos nos quais não existe qualquer biscoito diante de você - ou mundos nos quais o referido objeto está a mais de uma metro e meio de distância, ou até mesmo mundos nos quais o mesmo objeto foi movido para outro lugar. Nestes mundos particulares, em que o objeto em questão está ausente ou distante, você não acreditará que existe um biscoito a um metro e meio de distância de você. A conclusão é, portanto, a seguinte: você pode ter razões conclusivas para a proposição em questão, mas ela não pode ser caracterizada como heavyweight.

Para este caso particular, uma proposição genuinamente heavyweight seria, por exemplo, algo como: "existe um objeto real"28. McBride (2009, p. 125) observa que a alternativa relevante para esta proposição deve ser um mundo no qual não exista um objeto real. Ou seja: um mundo muito estranho, no qual tudo não passa de criação de sua mente que, apesar de muito poderosa, está bastante confusa. Em tais circunstâncias, você acreditaria na proposição "existe um objeto real" - que foi baseada em sua "percepção" de um biscoito - mesmo que não existisse tal objeto. Porém, novamente, isso significa dizer que você carece de razões conclusivas para esta proposição.

McBride não alcançou uma solução definitiva para o problema do fecho epistêmico. Ele reconhece isso. Porém, ele realizou algo de grande importância, pois sua resposta a Hawthorne mostra algo curioso sobre o desafio de Dretske: apesar das muitas tentativas de solução, ele ainda continua de pé.

\section{CONCLUSÃO}

Observando o atual estado desta discussão, conclui-se que a discussão sobre o fecho ou sobre princípios de fecho-, em âmbito epistemológico, encontra-se em aberto. Uma das razões para isso, talvez, seja a de que muitos epistemólogos que se debruçam sobre esse problema parecem aceitar tacitamente a dicotomia "validade/invalidade" dos princípios de fecho, sem antes questionarem os pressupostos lógicos envolvidos, bem como suas pretensões de aplicação para os respectivos princípios. Assim sendo, acredita-se que uma análise epistemológica de princípios de fecho que utilize recursos formais advindos da lógica epistêmica talvez possa contribuir de modo muito positivo para esse debate.

\footnotetext{
${ }^{28}$ A proposição original, em inglês, é "there is a mind-independent object."

DIALEKTIKÉ, v. 1, novembro 2014, p. 109-133

Artigo submetido em fevereiro/2014 e aceito em junho/2014
} 


\section{REFERÊNCIAS}

BONJOUR, Lawrence. Nozick, externalism and skepticism. In: LUPER-FOY, S. (org.). The possibility of knowledge. Lanham: Roman and Littlefield, 1987.

DE ALMEIDA, Cláudio. Closure, defeasibility and conclusive reasons. Acta Analytica, v. 22, n. 4, p. 301-319, dez. 2007.

DEROSE, Keith. Solving the skeptical problem. The Philosophical Review, v. 104, n. 1, p. 152, jan. 1995.

DRETSKE, Fred. I. Epistemic operators. The Journal of Philosophy, v. 67, n. 24, p. 10071023, dez. 1970. mai. 1971.

. Conclusive Reasons. Australasian Journal of Philosophy, v. 49, 210 n. 1, p. 1-22,

The case against closure. In: STEUP, M.; TURRI, J.; SOSA, E. (Org.). Contemporary debates in epistemology. Malden: Wiley-Blackwell, 2014, p. 27-40.

Reply to Hawthorne. In: STEUP, M.; TURRI, J.; SOSA, E. (Org.). Contemporary debates in epistemology. Malden: Wiley-Blackwell, 2014, p. 56-59.

FELDMAN, Richard. Contextualism and skepticism. Noûs, v. 33, n. 13, p. 91-114, out. 1999.

FUMERTON, Richard, A. Nozick's epistemology. In: LUPER-FOY, S. (editor). The possibility of knowledge. Lanham: Roman and Littlefield, 1987.

HAWTHORNE, J. The case for closure. In: STEUP, M.; TURRI, J.; SOSA, E. (Org.). Contemporary debates in epistemology. Malden: Wiley-Blackwell, 2014, p. 40-56.

HENDRICKS, Vincent. Mainstream and formal epistemology. New York: Cambridge University Press, 2006.

HINTIKKA, Jaakko. Knowledge and Belief: an introduction to the logic of the two notions. New York: Cornell University Press, 1962.

KVANVIG, Jonathan L. Closure principles. Philosophy Compass, v. 1, n. 3, p. 256-267, mai. 2006.

MCBRIDE, Mark. Is knowledge closed under known entailment? The strange case of Hawthorne's "heavyweight conjuncts" (and other strange cases). Theoria, v. 75, n. 2, p. 117128, mai. 2009.

WILLIAMSON, Timothy. Knowledge and its Limits. Oxford: Oxford University Press, 2000. 